\title{
Optic Flow Influences Perceived Exertion During Cycling
}

\section{David Parry, Camilla Chinnasamy, and Dominic Micklewright University of Essex}

\begin{abstract}
Optic flow on the retina creates a perception of a person's movement relative to their surroundings. This study investigated the effect of optic flow on perceived exertion during cycling. Fifteen participants completed a $20-\mathrm{km}$ reference cycling time trail in the fastest possible time followed by three randomly counterbalanced $20-\mathrm{km}$ cycling trials. Optic flow, via projected video footage of a cycling course, either represented actual speed $\left(\mathrm{TT}_{\mathrm{NORM}}\right)$ or was varied by $-15 \%\left(\mathrm{TT}_{\mathrm{SLOW}}\right)$ and $+15 \%$ ( $\mathrm{TT}_{\mathrm{FAST}}$ ). During $\mathrm{TT}_{\mathrm{SLOW}}$, power output and ratings of perceived exertion (RPE), measured every $4 \mathrm{~km}$, were lower during $\mathrm{TT}_{\mathrm{SLOW}}$ compared with $\mathrm{TT}_{\mathrm{NORM}}$ and $\mathrm{TT}_{\mathrm{FAST}}$. There were no differences in heart rate or cadence. This study is the first to show that different rates of optic flow influence perceived exertion during cycling, with slower optic flow being associated with lower RPE and higher power output.
\end{abstract}

Keywords: sensation, perception, heart rate, vision, psychology, performance

Perceived exertion constitutes a global conscious awareness of the internal state of the body and its associated sensations during physical activity (Hampson, St. Clair Gibson, Lambert, \& Noakes, 2001; St. Clair Gibson et al., 2003). Physiological changes that occur during physical activity, particularly to the pulmonary system, cardiovascular system, and active muscles, trigger sensory receptors in the afferent division of the peripheral nervous system that are then conveyed through the central nervous system via interoceptive pathways to generate the conscious perception of exertion (Craig, 2003; Craig, 2009; Damasio, 2000). One interesting observation is that subjective perceptions of exertion are not always constant in circumstances where the physiological stressor is similar (St. Clair Gibson et al., 2003). St. Clair Gibson et al. proposed several psychological mediators of the apparent intraindividual variation in perceived exertion including motivation, emotion, task expectation, memory, and prior experience.

Evidence that the perception of interoceptive sensations is mediated can be found in studies such as McCabe, Rolls, Bilderbeck, and McGlone (2008), who found that the touch associated with rubbing identical creams was reported to be more pleasant and richer when the cream was labeled as "rich moisturizing cream"

David Parry, Camilla Chinnasamy, and Dominic Micklewright are with the Centre for Sports and Exercise Science, School of Biological Sciences, University of Essex, Colchester, UK. 
compared with "basic cream." Pain perception was also found to be a mediated process (Chen, Williams, Fitness, \& Newton, 2008; Gray \& Wegner, 2008), with some evidence that visually focusing on the affected body region has an analgesic effect on acute pain (Longo, Betti, Aglioti, \& Haggard, 2009). According to Rolls (2010), the way that internal sensations are perceived is somewhat influenced by associated affective values and subjective emotional experiences.

The perception of exertion may differ according to the environmental context in which exercise is performed. In a recent paper, Tucker and Noakes (2009) proposed that perceived exertion is not only the product of combined internal afferent signals, but also external and environmental cues. Crucially, their model proposes cyclic interactions between physiological processes and the external environmental that give rise to perceptual experience during exercise, which in turn is a key determinant of effort regulation. Evidence for this model is mainly derived from studies in which false feedback about speed, distance, or time has caused variation in perceived exertion, pacing behavior, and performance (Albertus et al., 2005; Ansley, Robson, St. Clair Gibson, \& Noakes, 2008; Ansley, Schabort, St. Clair Gibson, Lambert, \& Noakes, 2008; Baden, Mclean, Tucker, Noakes, \& St. Clair Gibson, 2005; Mauger, Jones, \& Williams, 2009; Micklewright, Papadopoulou, Swart, \& Noakes, 2010; Morton, 2009). Although false information feedback studies provide some insight about the mediating effects of external performance cues on perceptual experience during exercise, very little is known about whether exteroceptive cues, such as visual sensation or optic flow, have similar effects.

Optic flow is the expanding pattern of flow on the retina, caused by moving through an environment, that forms the representational basis of egomotion (Gibson, 1950; Wallach, 1987; Warren \& Rushton, 2009). Manipulating optic flow has been found to influence time and distance estimations in foraging honeybees (Esch \& Burns, 1996) and the removal of optic flow caused treadmill walkers to overestimate the distance they had covered (Proffitt, Stefanucci, Banton \& Epstein, 2003). If, as these studies show, variation in optic flow can affect distance estimation, then, consistent with the proposed model of Tucker \& Noakes (2009), there could be an associated effect on perceived exertion. Optic flow that has been slowed down could potentially act as a performance cue suggesting arrival at the end point of a known duration exertion task will occur later than that suggested by true optic flow or optic flow that has been sped up. Previous research has demonstrated a scalar positive linear relationship between ratings of perceived exertion (RPE) and exercise duration (Eston, Faulkner, St. Clair Gibson, Noakes, \& Parfitt., 2007; Faulkner, Parfitt, \& Eston, 2008; Joseph et al., 2008; Noakes, 2004), which has been referred to as the performance template (Tucker \& Noakes, 2009). The rate of increase in RPE can predict exercise duration almost from its onset (Crewe, Tucker, \& Noakes, 2008) and is independent of actual performance (Tucker et al., 2007). The effect that optic flow variation is know to have on distance estimation (Esch \& Burns, 1996; Proffitt et al., 2003) will therefore potentially influence the performance template with slower optic flow leading to a shallower rate of increase in RPE and faster optic flow leading to a steeper rate of increase in RPE.

The purpose of this study was to examine how perceived exertion during cycling responds to changes in optic flow. It was hypothesized that slower optic flow would provoke lower RPE and fast optic flow would provoke higher RPE compared with normal optic flow. 


\section{Methods}

\section{Participants}

Fifteen moderately trained competitive triathletes participated in this study (age $M 31.0, S D=13.6$ years; stature $M=176.1, S D=8.4 \mathrm{~cm}$; body mass $M=73.4$, $S D=9.8 \mathrm{~kg}$ ). All participants had been competing in either triathlon or cycling for at least 2 years $(M=36, S D=52$ months) and for three months before the study had trained at least five times each week $(M=8.5, S D=4.4)$ with an accumulated training time of at least $6 \mathrm{hr}(M=8.0, S D=3.0)$. Each participant provided written informed consent to take part in the study. The University of Essex ethics committee approved all procedures used in this study.

\section{Design}

A two-way repeated-measures experimental design was used in which participants performed a self-paced laboratory simulated $20-\mathrm{km}$ cycling reference time trial followed by three $20-\mathrm{km}$ cycling tasks under different optic flow conditions (condition factor). During the optic flow cycling tasks participants were asked to match their power output and cadence to the average values recorded in the reference time trial. Heart rate (HR) and RPE measurements were taken every $4 \mathrm{~km}$ (distance factor). Participants were randomly assigned to complete the three optic flow cycling trials in a counterbalanced order. Each participant performed all cycling trials at the same time of day $( \pm 1 \mathrm{hr})$ with a recovery interval varying between 3 and 7 days. On the first laboratory attendance, each participant completed a personal history questionnaire and had their body mass and stature measured.

\section{Cycling Ergometry}

Participants completed all cycling procedures using their own bicycle on a Computrainer Pro cycle trainer with RealVideo software (RacerMate, Seattle) that was calibrated according to manufacturer instructions. The Computrainer Pro consists of a roller and resistance unit, on which a standard bicycle is placed, with the rear tire sitting on the roller. The resistance is automatically adjusted based upon the mass of the rider and the estimated aerodynamic drag calculated for any given speed.

Each participant first performed a self-paced $20-\mathrm{km}$ reference time trial that they were instructed to complete in the fastest possible time and during which power output and pedaling cadence were continuously recorded. Participants then performed three 20-km cycling tasks under different optic flow conditions (described below). Participants were asked to match their power output and pedaling cadence to the average values calculated from their first self-paced time trial. It was necessary to give participants voluntary control of power and cadence in this way so that, consistent with the methods used by Mohler, Thompson, Creem-Regehr, Pick and Warren (2007), the projected video footage was coupled in a multiplicative way to the cyclists' actual power output. The alternative-fixed optic flow video footage-would allow us to precisely fix power and cadence, but, owing to the video being uncoupled to actual cycling behavior creates a far less realistic virtual experience. Thus, participants attempted to match the intensity and pace of cycling during the optic flow cycling tasks against their best self-paced time trial 
performance. When participants performed the first self-paced time trial, they were not aware that their performance would be used to set the intensity and pace of the following three optic flow cycling tasks.

Participants were asked to refrain from consuming solid food for $2 \mathrm{hr}$ before each test and caffeine $4 \mathrm{hr}$ before each test. Participants were permitted to drink water during the first self-paced time trial and the same amount of water was provided for each of the three fixed-pace cycling tasks. Before each cycling task, participants performed a 5-min self-paced warm-up with a 5-min rest interval.

\section{Optic Flow Simulation}

During the optic flow cycling tasks, participants were instructed to observe video footage of a real road being traveled along, which was projected onto a large screen in front of them. Unknown to the participants, the speed of the video footage (optic flow) was varied in each condition so that it either matched their true cycling speed $\left(\mathrm{TT}_{\mathrm{NORM}}\right)$, was $15 \%$ slower than their true cycling speed $\left(\mathrm{TT}_{\mathrm{SLOW}}\right)$ or was $15 \%$ faster than their true cycling speed $\left(\mathrm{TT}_{\mathrm{FAST}}\right)$. Variation in optic flow was achieved by altering the virtual aerodynamic drag of the rider within the Computrainer software, which the Computrainer uses to alter the relationship between power output and rate of forward velocity of the video footage. As previously described, participants were randomly allocated to perform the three cycling tasks in a counterbalanced order of optic flow conditions. During a postexperimental debrief, it was confirmed that participants were unaware of the variation in optic flow.

\section{Psychophysiological Measures}

Heart rate was recorded continuously during each of the three optic flow cycling tasks using Computrainer Laboratory software (RacerMate, Seattle) via a wireless chest strap (Polar Electro, Finland) worn by each participant. Heart rate for each 4-km increment of the cycling tasks was subsequently calculated as the average value of the preceding $30 \mathrm{~s}$ of HR data. During each cycling task, participants were asked to provide an overall rating of perceived exertion at 4-km increments using the Borg 6-20 RPE scale (Borg, 1970). Each participant was familiarized with the RPE scale, which was administered in accordance with published standardized instructions (Borg, 1998). The experimental design is illustrated in Figure 1.

\section{Statistical Analysis}

All statistical analysis was performed using SPSS version 18. Two-way repeatedmeasures ANOVAs were used to analyze condition-by-distance differences in RPE and HR. Average power output and cadence were compared using one-way repeatedmeasures ANOVAs to check for any extraneous effects on RPE and HR outcomes. Two different statistical methods were then used to control for any variations in power output or cadence between optic flow conditions. The first involved normalizing both RPE and heart rate by diving them by (i) average power output and (ii) average cadence for each 4-km segment. The normalized data were then simply reanalyzed using two-way repeated-measures ANOVAs. The second approach involved conducting two-way repeated-measured ANCOVAs using average power and average cadence for each 4-km segment as covariates. This was done using SPSS syntax. 


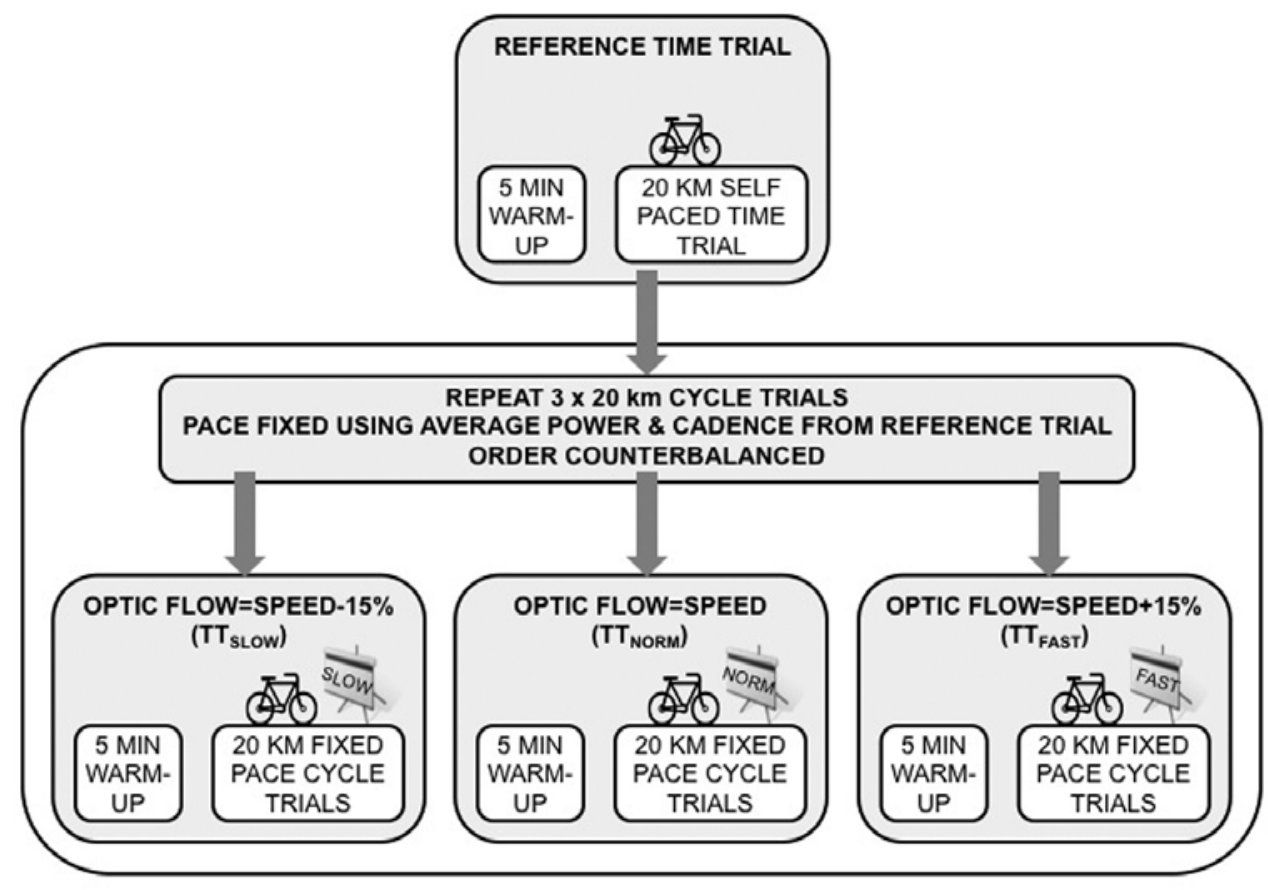

Figure 1 - Experimental protocol illustrating the self-paced reference $20-\mathrm{km}$ cycling time trial and three randomly counterbalanced fixed-pace cycling tasks performed under different optic flow conditions.

In accordance with Jennings and Wood (1976), Greenhouse-Geisser epsilon values $(\varepsilon)$ are reported together with adjusted $F$ statistics and $p$-values to safeguard against the increased risk of a Type I statistical error associated with repeated-measures psychophysiological studies. Any interactions and main effects were further analyzed using Bonferroni-corrected post hoc paired samples $t$ tests. The linear regression line gradients for RPE/distance and heart rate/distance were calculated for each participant individually and then compared between conditions using oneway repeated-measures ANOVAs with Greenhouse-Geisser $\varepsilon$-corrected values. Any differences were investigated using Bonferroni-corrected post hoc paired samples $t$ tests. All results are expressed as means with one standard deviation and effect sizes as partial eta squared $\left(\eta_{\mathrm{p}}^{2}\right)$ or eta squared $\left(\eta^{2}\right)$.

\section{Results}

\section{Self-Paced 20-km Time Trial Performance and Cycling Task Performances}

The average completion time for the self-paced 20-km time trial was $M=38: 25$, $S D=3: 42$ (minutes:seconds). Average power output was $M=195, S D=37 \mathrm{~W}$ and 
average pedaling cadence was $M=92.9, S D=8.6 \mathrm{rpm}$. No difference in cadence was found between the three optic flow cycling task conditions, $\varepsilon=.74, F(2,24)=$ $1.6, p=.218, \eta_{\mathrm{p}}{ }^{2}=.12$, but a difference in power output was found, $\varepsilon=.99, F(2,28)$ $=5.6, p=.008, \eta_{\mathrm{p}}^{2}=.29$. Bonferroni-corrected post hoc paired samples $t$ tests revealed that average power was higher during $\mathrm{TT}_{\text {SLOw }}$ compared with $\mathrm{TT}_{\text {NORM }}$, $M=199.1, S D=35.5$ vs. $M=195.5, S D=36.5 \mathrm{~W}, t(14)=2.7, p=.017, \eta^{2}=.34$, and $\mathrm{TT}_{\mathrm{FAST}} M=199.1, S D=35.5$ vs. $M=194.8, S D=36.3 \mathrm{~W}, t(14)=3.2, p<$ $.006, \eta^{2}=.42$. There was no difference in average power output during $\mathrm{TT}_{\mathrm{NORM}}$ and $\mathrm{TT}_{\mathrm{FAST}}$ conditions, $M=195.5, S D=36.5$ vs. $M=194.8, S D=36.3 \mathrm{~W}, t(14)$ $=0.5, p=.612, \eta^{2}=.02$.

\section{Ratings of Perceived Exertion}

Two-way within-subjects ANOVA showed no condition-by-distance interaction for RPE, $\varepsilon=.52, F(8,112)=1.1, p=.401, \eta_{\mathrm{p}}{ }^{2}=.07$, but there was a condition main effect, $\varepsilon=.98, F(2,28)=6.1, p=.006, \eta_{\mathrm{p}}{ }^{2}=.30$, and a distance main effect, $\varepsilon=$ $.33, F(4,56)=39.9, p<.001, \eta_{\mathrm{p}}{ }^{2}=.74$. After controlling for variations in average power using a two-way within-subjects ANCOVA, the condition main effect remained significant, $F(2,27)=3.8, p=.037, \eta_{\mathrm{p}}^{2}=.22$, and there was a significant distance main effect, $F(4,55)=42.9, p<.001, \eta_{\mathrm{p}}{ }^{2}=.76$, but there was no condition-by-distance interaction, $F(8,111)=1.6, p=.146, \eta_{\mathrm{p}}{ }^{2}=.10$. For normalized RPE scores, there was a condition main effect, $\varepsilon=.99, F(2,28)=10.5, p<.001$, $\eta_{\mathrm{p}}{ }^{2}=.43$; a distance main effect, $\varepsilon=.35, F(4,56)=22.2, p<.001, \eta_{\mathrm{p}}{ }^{2}=.64$; and a condition-by-distance interaction, $\varepsilon=.54, F(8,112)=3.2, p=.002, \eta_{\mathrm{p}}^{2}=.19$.

Post hoc paired samples $t$ tests with a Bonferroni-corrected alpha level of .0167 revealed lower average $\mathrm{RPE}$ during $\mathrm{TT}_{\mathrm{SLO}}$ compared with $\mathrm{TT}_{\mathrm{NORM}}, M=14.3, S D$ $=1.0$ vs. $M=14.9, S D=1.0, t(14)=-2.6, p=.011, \eta^{2}=0.33$, and $\mathrm{TT}_{\mathrm{FAST}}, M=$ $14.3, S D=1.0$ vs. $M=15.1, S D=0.8, t(14)=-3.3, p=.003, \eta^{2}=.44$. Average RPE during $\mathrm{TT}_{\text {NORM }}$ was no different from average RPE during $\mathrm{TT}_{\mathrm{FAST}}, M=14.9$, $S D=1.0$ vs. $M=15.1, S D=0.8, t(14)=-1.0, p=.174, \eta^{2}=.07$. Condition-bydistance outcomes for RPE and normalized RPE are presented in Figures 2A and $2 \mathrm{~B}$ respectively.

\section{Heart Rate}

Three of the participants had spoiled HR data, meaning that the analysis could be conducted only for 12 participants. Two-way within-subjects ANOVA showed no condition-by-distance interaction for $\mathrm{HR}, \varepsilon=.45, F(8,88)=1.0, p=.475, \eta_{\mathrm{p}}{ }^{2}=.08$, and no condition main effect, $\varepsilon=.57, F(2,22)=0.6, p=.552, \eta_{\mathrm{p}}{ }^{2}=.05$, but there was a distance main effect, $\varepsilon=.42, F(4,44)=5.7, p<.001, \eta_{\mathrm{p}}{ }^{2}=.34$. After controlling for variations in average power using a two-way within-subjects ANCOVA, the distance main effect remained significant, $F(4,43)=5.4, p=.001, \eta_{\mathrm{p}}{ }^{2}=.33$, but the condition main effect remained not significant, $F(2,21)=0.7, p=.489, \eta_{\mathrm{p}}{ }^{2}$ $=.07$, and the condition-by-distance interaction remained not significant, $F(8,87)$ $=0.8, p=.634, \eta_{\mathrm{p}}{ }^{2}=.07$. For normalized HR values, there was no condition main effect, $\varepsilon=.53, F(2,22)=1.1, p=.334, \eta_{\mathrm{p}}{ }^{2}=.09$; no distance main effect, $\varepsilon=.29$, $F(4,44)=2.1, p<.091, \eta_{\mathrm{p}}{ }^{2}=.16$; and no condition-by-distance interaction, $\varepsilon=$ $.50, F(8,88)=0.8, p=.534, \eta_{\mathrm{p}}^{2}=.07$. Condition-by-distance outcomes for HR and normalized $\mathrm{HR}$ are presented in Figures $3 \mathrm{~A}$ and $3 \mathrm{~B}$ respectively. 

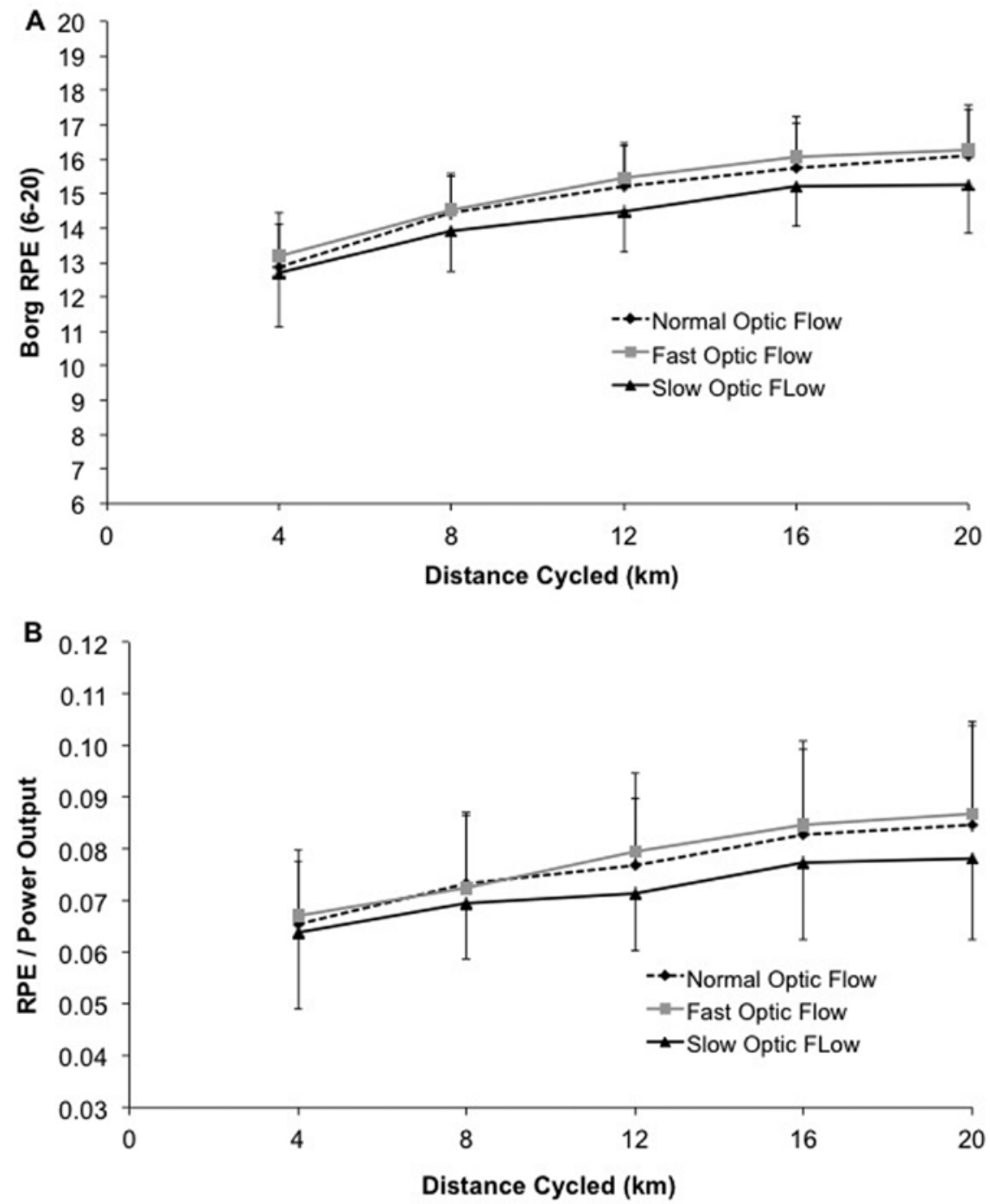

Figure 2 - Optic flow condition-by-distance outcomes for absolute RPE values (A) and RPE normalized for power output (B). 

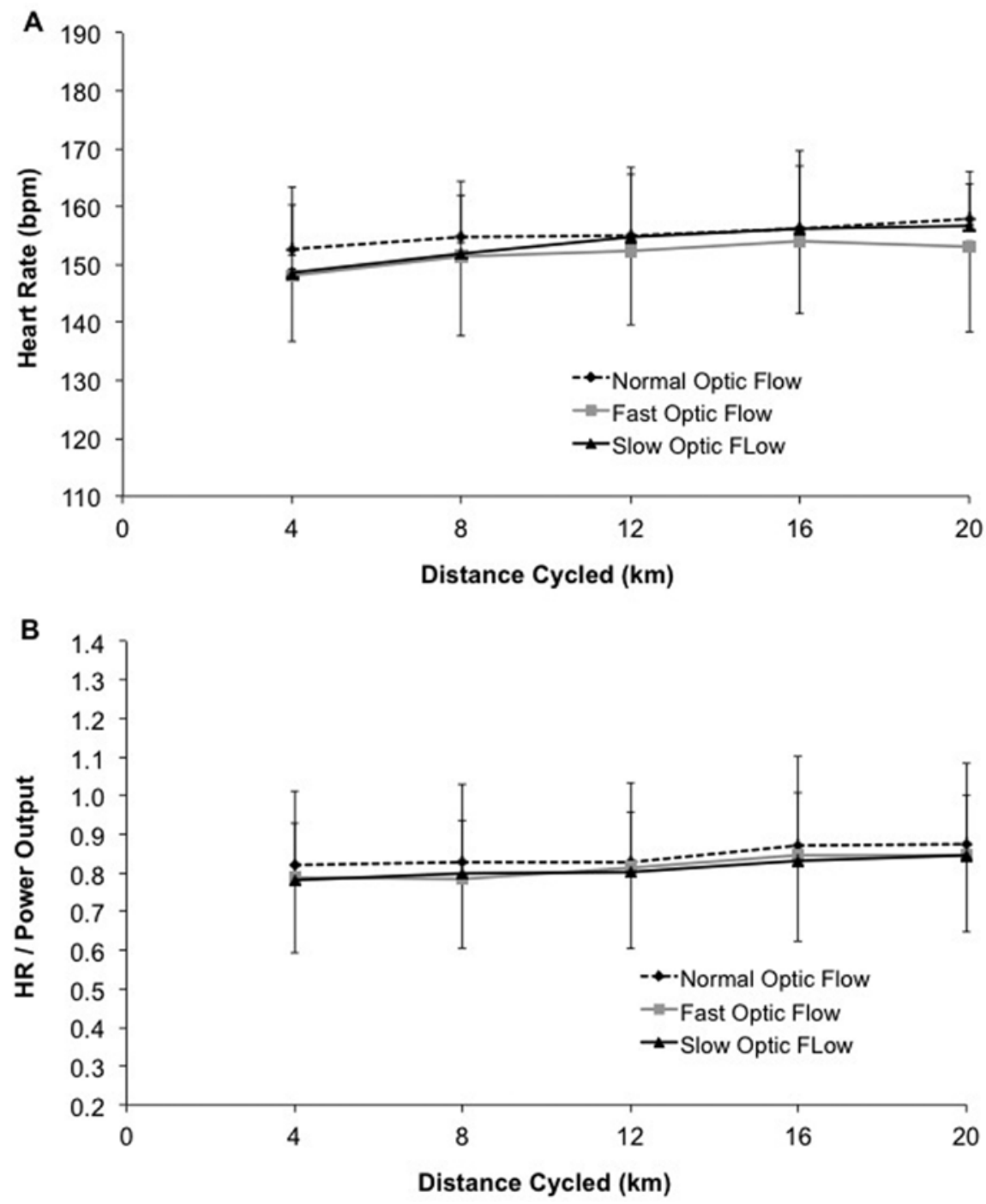

Figure 3 - Optic flow condition-by-distance outcomes for absolute heart rate values (A) and heart rate values normalized for power output (B). 


\section{Rate of Increase in RPE and Heart Rate Against Distance Cycled}

A significant difference between optic flow conditions was found for the RPE/ Distance linear regression line gradients, $\varepsilon=.90, F(2,28)=4.4, p=.023, \eta_{\mathrm{p}}{ }^{2}=.25$, but there was no difference for the HR/Distance linear regression line gradients, $\varepsilon=$ $.56, F(2,24)=1.9, p=.17, \eta_{\mathrm{p}}{ }^{2}=.14$. Post hoc Bonferroni-corrected paired samples $t$ tests revealed $\mathrm{TT}_{\mathrm{SLOW}}$ had a shallower RPE/Distance gradient compared with both $\mathrm{TT}_{\mathrm{NORM}}, M=0.16, S D=0.11$ vs. $M=0.19, S D=0.11, t(14)=-2.0, p=.031, \eta^{2}$ $=0.22$, and $\mathrm{TT}_{\mathrm{FAST}}, M=0.16, S D=0.11$ vs. $M=0.20, S D=0.12, t(14)=-2.5, p$ $=.013, \eta^{2}=.31$ ), but no difference was found between $\mathrm{TT}_{\mathrm{NORM}}$ and $\mathrm{TT}_{\mathrm{FAST}}, M=$ $0.19, S D=0.11$ vs. $M=0.20, S D=0.12, t(14)=-0.9, p=.361, \eta^{2}=.06$.

\section{Discussion}

The main finding of our study is that optic flow influences perceived exertion during cycling, with slower optic flow being found to cause lower RPE and a shallower increase in RPE gradient. A further interesting finding of the study is that, despite being instructed to match power and cadence, participants cycled at a higher power output during $\mathrm{TT}_{\mathrm{SLOW}}$. Our results show that slower optic flow has an influence on perceived exertion and has a contributory role in effort regulation during cycling.

\section{The Effect of Optic Flow on Perceived Exertion}

This is the first study to show that visual representations of egomotion influence the way internal physiological sensations are perceived during exercise. Once the differences in power output between optic flow conditions had been statistically controlled for, RPE remained lower during $\mathrm{TT}_{\mathrm{SLOW}}$. This finding is consistent with numerous other studies that, albeit focused on either touch or acute pain, have found an effect of exteroceptive information on the way internal sensory information is perceived (Blakemore, Bristow, Bird, Frith, \& Ward, 2005; Johansen-Berg \& Lloyd, 2000; Keysers et al., 2004; Longo et al., 2009; Mancini, Longo, Kammers, \& Haggard, 2011; McCabe et al., 2008; Schaefer, Flor, Heinze, \& Rotte, 2006;).

Contrary to our hypothesis, RPE during $\mathrm{TT}_{\mathrm{FAST}}$ did not differ from $\mathrm{TT}_{\mathrm{NORM}}$, meaning that perceived exertion is apparently only sensitive to optic flow that has been retarded. One potential reason may be that during $\mathrm{TT}_{\mathrm{SLO}}$ the sense of egomotion is suggestive of a longer time to completion. In keeping with performance template of pacing control (Swart et al., 2009; Tucker \& Noakes, 2009), this would mean that a shallower rate of increase in RPE would be required to ensure that the longer time to completion, suggested by $\mathrm{TT}_{\mathrm{SLOW}}$, is achieved without premature fatigue. Notwithstanding the condition variation in power output, the downward adjustment in RPE observed in our study during $\mathrm{TT}_{\text {SLOw }}$ appears to show an attempt by participants to modify the performance template to ensure they complete the cycling task. In contrast, $\mathrm{TT}_{\mathrm{FAST}}$ suggests a shorter time to completion and, since this does not constitute a threat to task completion in the performance template, no adjustment of RPE or power output is therefore needed and did not occur. In fact, a similar effect was reported in a study in which cyclists' time-to-exhaustion increased when shown a clock that had been manipulated to run slow, but a fasterrunning clock did not produce a significant change in time to exhaustion (Morton, 2009). Although it is not possible to explain the exact mechanisms responsible 
for this optic flow effect on the performance template, it is quite probable that the previously described role of optic flow on distance estimation (Esch \& Burns, 1996; Proffitt et al., 2003) is in some way involved.

\section{The Effect of Optic Flow on Power Output}

A higher power output was recorded during slow optic flow compared with the other conditions. Previous research demonstrated that self-selected walking velocity is affected by the rate of optic flow in a virtual environment (Mohler et al., 2007) and that preferred walking speed tends to minimize metabolic energy cost (Zarrugh \& Radcliffe, 1978). These findings show that optic flow is incorporated into the assessment of the work required to maintain a given walking velocity and that, similar to the performance template (Tucker \& Noakes, 2009), effort is modulated according to this integration of sensory information. Our findings are surprising because, rather than being allowed to self-select cycling intensity in different optic flow conditions, participants were explicitly instructed to match their power output and cadence to the reference cycling time-trial average values. It is therefore apparent that optic flow plays a contributory role in effort regulation that perhaps competes with any explicitly planned effort intentions.

A similar type of visual information dominance on the control of body movements has in fact been observed in proprioception studies. Lee and Aronson (1974) showed that children swayed and lost balance when placed in a room where the walls and ceiling moved from side to side even though the floor they were positioned on was fixed and stable. Slobounov et al. (2006) found similar effects using a virtual reality system to create the swinging room but, in addition to Lee and Aronson's findings, also recorded perception self-movement, or vection. Interestingly, optic flow induced vection has also been correlated with postural movement (Kuno, Kawakita, Kawakami, Miyake, \& Watanabe, 1999), which establishes an important relationship between the perceptual and motor responses to visual information about the environment. While these studies were primarily concerned with balance and proprioception, the underlying mechanism that visual information has a greater dominance than mechanical feedback is relevant in explaining the higher power output observed in our slow optic flow condition. We cannot conclude that optic flow has a dominant effect on effort regulation but our findings do indicate it has a contributory role.

The effects of optic flow on perceived exertion, when considered in the context of the performance template (Tucker \& Noakes, 2009), may also help to explain why power output changed at all. It has been suggested that perceived exertion provides the basis for effort regulation during exercise so that, over a given time or distance, catastrophic physiological failure and premature fatigue are averted (Lambert, St. Clair Gibson, \& Noakes, 2005; Noakes, St. Clair Gibson, \& Lambert, 2004; St. Clair Gibson \& Noakes, 2004). Any deviation of actual RPE from the expected RPE trajectory is thought to act as a pacing modification trigger (Parry, Chinnasamy, Papadopoulou, Noakes, \& Micklewright, 2011; Swart et al., 2009; Tucker $\&$ Noakes, 2009). Slow optic flow suggests that it will take longer to complete the 20-km cycling task compared with that experienced in the reference time trial, and for some participants, the other optic flow cycling tasks. The perceived longer duration constitutes a threat to task completion because the maximum tolerable RPE would occur before the end of the task. Participants essentially have two options that are to either cycle faster bringing about the end of the task sooner or, as previously 
discussed, modify the RPE performance template. Our findings have indicated that during $\mathrm{TT}_{\text {SLOW }}$ participants to some extent adopted both of these approaches.

\section{Conclusions}

This study is the first to show that different rates of optic flow influence perceived exertion during cycling, with slower optic flow being associated with lower RPE. The results also show participants produced more power during the slow optic flow condition. This seemingly unlikely combination of lower RPE together with higher power output appears to have been possible because, as previously discussed, slow optic flow has a contributory buffering effect on the way physiological sensations are perceived and power output was modified as a behavioral response to bring about faster progress ensuring task completion.

\section{References}

Albertus, Y., Tucker, R., St. Clair Gibson, A., Lambert, E.V., Hampson, D.B., \& Noakes, T.D. (2005). Effect of distance feedback on pacing strategy and perceived exertion during cycling. Medicine and Science in Sports and Exercise, 37, 461-468. PubMed doi:10.1249/01.MSS.0000155700.72702.76

Ansley, L., Robson, P.J., St. Clair Gibson, A., \& Noakes, T. (2004). Anticipatory pacing strategies during supramaximal exercise lasting longer than $30 \mathrm{~s}$. Medicine and Science in Sports and Exercise, 36(2), 309-314. PubMed

Ansley, L., Schabort, E., St. Clair Gibson, A., Lambert, M.I., \& Noakes, T. (2004). Regulation of pacing strategies during successive 4-km time trials. Medicine and Science in Sports and Exercise, 36(10), 1819-1825. PubMed

Baden, D.A., Mclean, T.L., Tucker, R., Noakes, T.D., \& St. Clair Gibson, A. (2005). effect of anticipation during unknown or unexpected exercise duration on rating of perceived exertion, affect, and physiological function. British Journal of Sports Medicine, 39, 742-746. PubMed doi:10.1136/bjsm.2004.016980

Blakemore, S.J., Bristow, D., Bird, G., Frith, C., \& Ward, J. (2005). Somatosensory activations during the observation of touch and a case of vision-touch synaesthesia. Brain, 128, 1571-1583. PubMed doi:10.1093/brain/awh500

Borg, G. (1970). Perceived exertion as an indicator of somatic stress. Scandinavian Journal of Rehabilitation Medicine, 2(2-3), 92-98. PubMed

Borg, G. (1998). Borg's perceived exertion and pain scales (pp. 44-49). Champaign, IL: Human Kinetics.

Chen, Z., Williams, K.D., Fitness, J., \& Newton, N.C. (2008). When hurt will not heal: Exploring the capacity to relive social and physical pain. Psychological Science, 19, 789-795. PubMed doi:10.1111/j.1467-9280.2008.02158.x

Craig, A.D. (2003). A new view of pain as a homeostatic emotion. Trends in Neurosciences, 26, 303-307. PubMed doi:10.1016/S0166-2236(03)00123-1

Craig, A.D. (2009). How do you feel now? The anterior insula and human awareness. Nature Reviews. Neuroscience, 10, 59-70. PubMed doi:10.1038/nrn2555

Crewe, H., Tucker, R., \& Noakes, T.D. (2008). The rate of increase in rating of perceived exertion predicts the duration of exercise to fatigue at a fixed power output in different environmental conditions. European Journal of Applied Physiology, 103, 569-577. PubMed doi:10.1007/s00421-008-0741-7

Damasio, A. (2000). The feeling of what happens: body, emotion and the making of consciousness (pp. 149-153). Reading: Vintage.

Esch, H.E., \& Burns, J.E. (1996). Distance estimation by foraging honeybees. The Journal of Experimental Biology, 199, 155-162. PubMed 
Eston, R., Faulkner, J.A., St. Clair Gibson, A., Noakes, T., \& Parfitt, G. (2007). The effect of antecedent fatiguing activity on the relationship between perceived exertion and physiological activity during a constant load exercise task. Psychophysiology, 44, 779-786. PubMed doi:10.1111/j.1469-8986.2007.00558.x

Faulkner, J., Parfitt, G., \& Eston, R. (2008). The rating of perceived exertion during competitive running scales with time. Psychophysiology, 45, 977-985. PubMed doi:10.1111/ j.1469-8986.2008.00712.x

Gibson, J.J. (1950). The perception of the visual world (pp. 131-136). Boston: Houghton Mifflin.

Gray, K., \& Wegner, D.M. (2008). The sting of intentional pain. Psychological Science, 19, 1260-1262. PubMed doi:10.1111/j.1467-9280.2008.02208.x

Hampson, D.B., St. Clair Gibson, A., Lambert, M.I., \& Noakes, T.D. (2001). The influence of sensory cues on the perception of exertion during exercise and central regulation of exercise performance. Sports Medicine (Auckland, N.Z.), 31, 935-952. PubMed doi:10.2165/00007256-200131130-00004

Jennings, J.R., \& Wood, C.C. (1976). The $\varepsilon$-adjustment procedure for repeatedmeasures analyses of variance. Psychophysiology, 13(3), 277-278. PubMed doi:10.1111/j.1469-8986.1976.tb00116.x

Johansen-Berg, H., \& Lloyd, D.M. (2000). The physiology and psychology of selective attention to touch. Frontiers in Bioscience, 5, D894-D904. PubMed doi:10.2741/berg

Joseph, T., Johnson, B., Battista, R.A., Wright, G., Dodge, C., Porcari, J.P., . . Foster, C. (2008). Perception of fatigue during simulated competition. Medicine and Science in Sports and Exercise, 40, 381-386. PubMed doi:10.1249/mss.0b013e31815a83f6

Keysers, C., Wicker, B., Gazzola, V., Anton, J.L., Fogassi, L., \& Gallese, V. (2004). A touching sight: SII/PV activation during the observation and experience of touch. Neuron, 42, 335-346. PubMed doi:10.1016/S0896-6273(04)00156-4

Kuno, S., Kawakita, T., Kawakami, O., Miyake, Y., \& Watanabe, S. (1999). Postural adjustment response to depth direction of moving patterns pro- duced by virtual reality graphics. Japanese Journal of Physiology, 49(5), 417-424. PubMed doi:10.2170/ jjphysiol.49.417

Lambert, E.V., St Clair Gibson, A., \& Noakes, T.D. (2005). Complex systems model of fatigue: integrative homeostatic control of peripheral physiological systems during exercise in humans. British Journal of Sports Medicine, 39, 52-62. PubMed doi:10.1136/ bjsm.2003.011247

Lee, D.N., \& Aronson, E. (1974). Visual proprioceptive control of standing in human infants. Attention, Perception \& Psychophysics, 15(3), 529-532.

Longo, M.R., Betti, V., Aglioti, S.M., \& Haggard, P. (2009). Visually induced analgesia: Seeing the body reduces pain. The Journal of Neuroscience, 29, 12125-12130. PubMed doi:10.1523/JNEUROSCI.3072-09.2009

Mancini, F., Longo, M.R., Kammers, M.P.M., \& Haggard, P. (2011). Visual distortion of body size modulates pain perception. Psychological Science. Advance online publication. doi:10.1177/0956797611398496.

Mauger, A.R., Jones, A.M., \& Williams, C.A. (2009). Influence of feedback and prior experience on pacing during a 4-km cycle time trial. Medicine and Science in Sports and Exercise, 41(2), 451-458. PubMed doi:10.1249/MSS.0b013e3181854957

McCabe, C., Rolls, E.T., Bilderbeck, A., \& McGlone, F. (2008). Cognitive influences on the affective representation of touch and the sight of touch in the human brain. SCAN, 3, 97-108. PubMed

Micklewright, D., Papadopoulou, E., Swart, J., \& Noakes, T. (2010). Previous experience influences pacing during 20-km time trial cycling. British Journal of Sports Medicine, 44, 952-960. PubMed doi:10.1136/bjsm.2009.057315

Mohler, B.J., Thompson, W.B., Creem-Regehr, S.H., Pick, H.L., Jr., \& Warren, W.H., Jr. (2007). Visual flow influences gait transition speed and preferred walking speed. Experimental Brain Research, 181(2), 221-228. PubMed doi:10.1007/s00221-007-0917-0 
Morton, R.H. (2009). Deception by manipulating the clock calibration influences cycle ergometer endurance time in males. Journal of Science and Medicine in Sport, 12, 332-337. PubMed doi:10.1016/j.jsams.2007.11.006

Noakes, T.D. (2004). Linear relationship between the perception of effort and the duration of constant load exercise that remains. Journal of Applied Physiology, 96, 1571-1572. PubMed doi:10.1152/japplphysiol.01124.2003

Noakes, T.D., St. Clair Gibson, A., \& Lambert, E.V. (2004). From catastrophe to complexity: a novel model of integrative central neural regulation of effort and fatigue during exercise in humans. British Journal of Sports Medicine, 38, 511-514. PubMed doi:10.1136/bjsm.2003.009860

Parry, D., Chinnasamy, C., Papadopoulou, E., Noakes, T., \& Micklewright, D. (2011). Cognition and Performance: Anxiety, Mood and Perceived Exertion among Ironman Triathletes. British Journal of Sports Medicine, 45(14), 1088-1094. PubMed

Proffitt, D.R., Stefanucci, J., Banton, T., \& Epstein, W. (2003). The role of effort in perceiving distance. Psychological Science, 14, 106-112. PubMed doi:10.1111/1467-9280.t01-1-01427

Rolls, E.T. (2010). The affective and cognitive processing of touch, oral texture, and temperature in the brain. Neuroscience and Biobehavioral Reviews, 34, 237-245. PubMed doi:10.1016/j.neubiorev.2008.03.010

Schaefer, M., Flor, H., Heinze, H.J., \& Rotte, M. (2006). Dynamic modulation of the primary somatosensory cortex during seeing and feeling a touched hand. NeuroImage, 29, 587-592. PubMed doi:10.1016/j.neuroimage.2005.07.016

Slobounov, S., Wu, T., Hallett, M., Shibasaki, H., Slobounov, E., Newell, K. (2006). Neural underpinning of postural responses to visual field motion. Biological Psychology, 72(2), 188-197. PubMed doi:10.1016/j.biopsycho.2005.10.005

St. Clair Gibson, A., \& Noakes, T.D. (2004). Evidence for complex system integration and dynamic neural regulation of skeletal muscle recruitment during exercise in humans. British Journal of Sports Medicine, 38, 797-806. PubMed doi:10.1136/ bjsm.2003.009852

St. Clair Gibson, A., Baden, D.A., Lambert, M.I., Lambert, E.V., Harley, Y.X., Hampson, D., . . Noakes, T.D. (2003). The conscious perception of the sensation of fatigue. Sports Medicine (Auckland, N.Z.), 33, 167-176. PubMed doi:10.2165/00007256200333030-00001

Swart, J., Lamberts, R.P., Lambert, M.I., Lambert, E.V., Woolrich, R.W., Johnston, S., \& Noakes, T.D. (2009). Exercising with reserve: exercise regulation by perceived exertion in relation to duration of exercise and knowledge of endpoint. British Journal of Sports Medicine, 43, 775-781. PubMed doi:10.1136/bjsm.2008.056036

Tucker, R., Kayser, B., Rae, E., Raunch, L., Bosch, A., \& Noakes, T. (2007). Hyperoxia improves $20 \mathrm{~km}$ cycling time trial performance by increasing muscle activation levels while perceived exertion stays the same. European Journal of Applied Physiology, 101, 771-781. PubMed doi:10.1007/s00421-007-0458-z

Tucker, R., \& Noakes, T. D. (2009). The physiological regulation of pacing strategy during exercise: A critical review. British Journal of Sports Medicine, Advance online publication. doi:10.1136/bjsm.2009.057562

Wallach, H. (1987). Perceiving a stable environment when one moves. Annual Review of Psychology, 38, 1-27. PubMed doi:10.1146/annurev.ps.38.020187.000245

Warren, P.A., \& Rushton, S.K. (2009). Optic flow processing for the assessment of object movement during ego movement. Current Biology, 19, 1555-1560. PubMed doi:10.1016/j.cub.2009.07.057

Zarrugh, M.Y., \& Radcliffe, C.W. (1978). Predicting metabolic cost of level walking. European Journal of Applied Physiology and Occupational Physiology, 38(3), 215-223. PubMed doi:10.1007/BF00430080

Manuscript submitted: March 29, 2011

Revision accepted: April 1, 2012 